

\title{
La intervención de Pedro I de Castilla en el alcázar de Carmona
}

\author{
The Intervention of Pedro I of Castile in the Alcázar of Carmona
}

Pablo Gumiel Campos

Universidad Autónoma de Madrid, España

Parques de Sintra Monte da Lua, Portugal

gumiel.pablo@gmail.com

https://orcid.org/0000-0001-9632-8358

Recepción: 29/01/2020 | Aceptación: 23/03/2020

\section{Resumen}

La ciudad de Carmona en el siglo XIV actuaba como la plaza fuerte de Sevilla y contaba con tres alcázares fortificados más un perimetro amurallado circundante a todo el casco urbano. Estos eran el alcázar de Abajo en el oeste de la ciudad, el alcázar de Puerta de Córdoba en el noreste, y el alcázar de Arriba en el este. Este último era la principal fortaleza de la ciudad desde época islámica. Bajo el reinado de Pedro I, se llevaron a cabo una serie de modificaciones en este castillo. Se reforzaron sus sistemas defensivos en el contexto de la guerra civil castellana, pero también se inició la construcción de un palacio en el interior a semejanza de los que se estaban construyendo en el resto de Castilla bajo la promoción de dicho monarca. Este artículo pretende analizar cuál fue la intervención específica del rey Pedro I sobre el alcázar carmonense.

\section{Abstract}

In the fourteenth century, the city of Carmona was the stronghold of Seville, boasting three fortified alcázars as well as a perimeter wall around the entire urban area. These included the lower alcázar in the western part of the city, the Puerta de Córdoba alcázar on the northwest side, and the upper alcázar in the East. The latter acted as the city's main fortification since Islamic times. A series of changes were made to the castle under the reign of Pedro l; its defense systems were strengthened during the Castilian Civil War, and a palace was constructed in its interior, resembling others built by the monarch throughout the kingdom of Castile. In this paper we aim to analyse the specific intervention of King Pedro I in the Alcázar of the city of Carmona.
Palabras clave

Carmona
Pedro I
Alcázar
Castilla
Arquitectura medieval
Palacio

Palacio

\section{Keywords}

Carmona

Pedro I

Alcázar

Castile

Medieval Architecture

Palace 


\section{Historiografía}

El alcázar de Arriba de Carmona ha sido objeto de estudio desde el siglo XVII. En el año 1621 Salvador Bautista de Arellano, publicó un volumen recopilando la historia y los principales monumentos de la villa de Carmona'. La relevancia de dicha publicación radica especialmente en su valor testimonial. Bautista de Arellano pudo contemplar el alcázar carmonense antes de su destrucción y consecuente abandono tras el terremoto de Lisboa de 1755. En su texto podemos constatar por ejemplo cómo el patio de la Fuente, que posteriormente estudiaremos, tenía un alzado en estilo "arábigo": "En lo último del Alcaçar ay un hermoso patio en ladrillado có muchas colunas, cornisamento y pedestales, las puertas de las salas con artesones de oro, y las paredes labradas a lo Arabigo"2.

Tras la publicación de Bautista de Arellano, tendremos que esperar más de dos siglos hasta que el edificio despertara de nuevo el interés de los investigadores. En 1886 un arqueólogo anglo-francés Ilamado George Edward Bonsor, realizó el primer levantamiento planimétrico del edificio que ha seguido vigente hasta las últimas aportaciones de Antonio Almagro Gorbea. Los trabajos de Bonsor pronto empezaron a despertar el interés de algunos vecinos ilustres de la villa. Los hermanos Juan y Manuel Fernández López se reunieron con George Bonsor para estudiar el patrimonio local fundando la Sociedad Arqueológica de Carmona, que llevó a cabo dos excavaciones en el recinto del alcázar. La primera se desarrolló entre 1886 y 1888, mientras que la segunda tuvo lugar entre 1894 e inicios del siglo XX³. En estas excavaciones, en las que también participaron Aniceto de la Cuesta, José Pérez Cassini y José Vega y Peláez, se sacaron a la luz una serie de restos arqueológicos de importancia. Se encontraron silos, pavimentos, aljibes, un sepulcro romano con restos de cerámica, pero lo más relevante para nuestro estudio: una serie de azulejos en el lugar donde debió estar situada la capilla privada del palacio4.

Además de los trabajos arqueológicos efectuados por la Sociedad Arqueológica de Carmona, Manuel Fernández López también publicó un importante manual sobre la historia de Carmona en el cual incluyó una magnífica descripción del alcázar ${ }^{5}$. Para realizar

1. Salvador Bautista de Arellano, Antigüedades y excelencias de la villa de Carmona y compendio de sus historias (Sevilla: Simón Faxarao, 1621).

2. Bautista de Arellano, 101.

3. Rocío Anglada Curado y Ventura Galera Navarro, "El Alcázar de Arriba de Carmona," Castillos de España, no. 125 (2002): 49.

4. Juan Fernández López, "Memoria resumen de los trabajos realizados por la Sociedad Arqueológica de Carmona," en Memorias de la Sociedad Arqueológica de Carmona (Carmona: Imp. La Verdad, 1887), 28.

5. Manuel Fernández y López, Historia de la Ciudad de Carmona, desde los tiempos más remotos hasta el reinado de Carlos I(Sevilla: Imprenta y Litografía de Gironés y Orduña, 1886). 
esta descripción el autor se basó en las fuentes de Bautista de Arellano a la par que en los descubrimientos arqueológicos de la sociedad. Manuel Fernández consideró por primera vez que el alcázar debía ser obra de los mismos artífices que el palacio sevillano: "Baste decir que los mismos artífices que trabajaron en el alcázar de Sevilla lo hicieron también en el de la puerta de Marchena, dejando en éste no menos primores y detalles de ejecución que en aquél".

En 1953, se elaboró el catálogo arqueológico y artístico de la provincia de Sevilla7. Entonces, los investigadores José Hernández Díaz, Antonio Sancho Corbacho, y Francisco CoIlantes de Terán consideraron que el alcázar de Carmona en tiempos del rey Pedro I debió sufrir una restauración de un antiguo palacio, por lo que no sería una obra de nueva planta ${ }^{8}$.

Durante los años setenta, se inició el proyecto de construcción de un parador nacional dentro del recinto del alcázar de Carmona. El nuevo trazado contempló la restauración absoluta de todo el edificio, sin embargo el arquitecto y profesor Rafael Manzano Martos sugirió que el parador se ubicara en el espacio situado al sur de los restos del palacio, en el lugar donde antiguamente se emplazaba el patio de armas del edificio. Esta localización, que finalmente fue la decisiva, evitó la destrucción de los escasos restos arqueológicos que se han preservado del palacio ${ }^{9}$. En los mismos años setenta, el estudio del alcázar, se vio complementado por los grandes compendios documentales de Manuel González Jiménez ${ }^{10}$.

En el año 1987 a raíz de una propuesta de ampliación del parador nacional, volvió a despertarse el interés arqueológico por el edificio. Ricardo Lineros, responsable del Servicio Municipal de Arqueología de Carmona, llevó a cabo una serie de excavaciones de urgencia. Estas excavaciones tuvieron lugar en un emplazamiento situado junto al lienzo sur del tercer recinto, entre la torre Mayor y la puerta de la Piedad"11. El objetivo era determinar los diversos estratos arqueológicos del área muestreada. Los arqueólogos

6. Fernández y López, 281.

7. José Hernández Díaz, Antonio Sancho Corbacho, y Francisco Collantes de Terán, Catálogo arqueológico y artístico de la provincia de Sevilla, vol. 2 (Sevilla: Excelentísima Diputación Provincial de Sevilla, 1953).

8. Hernández Díaz, Sancho Corbacho, y Collantes de Terán, 221.

9. Olga María Guerrero Chamero, "El Alcázar de Arriba de Carmona, metodología de estudios arqueológicos durante el proceso de obra de restauración - conservación" (trabajo fin de máster, Universidad de Sevilla, 2017), 19.

10. Manuel González Jiménez, Ordenanzas del Concejo de Carmona (Sevilla: Publicaciones de la Excma. Diputación Provincial de Sevilla, 1972); Archivo de la Universidad de Beneficiados de Carmona: catálogo de documentación medieval (Sevilla: Publicaciones de la Excma. Diputación Provincial de Sevilla, 1974); Catalogo de documentación medieval del Archivo Municipal de Carmona (1249-1474)(Sevilla: Publicaciones de la Excma. Diputación Provincial de Sevilla, 1976).

11. Rosario Cardenete y Ricardo Lineros, "Avance de los resultados obtenidos en las excavaciones de los solares Jorge Bonsor $n^{0}$ 22, Alcázar de Arriba y real nํ 32," Anuario arqueológico de Andalucía 1987, t. 3 Actividades de Urgencia (1990): 569. 
concluyeron la existencia de restos en dos niveles. Por un lado, un primer estrato "con materiales de época romana encuadrables con considerable laxitud entre los siglos I a. C y II d.C." "12. Por otro lado en el estrato superior documentaron "una actividad constructiva importante en tiempos del alcázar cristiano"13. Aunque no hallaron ningún resto de época islámica, los arqueólogos aceptaron que la documentación histórica atestigua la presencia musulmana en el área.

En el año 1997 la revista Archivo Hispalense, dedicó un número monográfico a las actas del primer congreso de historia de Carmona. En dicho coloquio se plantearon importantes comunicaciones para el estudio del alcázar. Luis de Mora-Figueroa ${ }^{14}$ presentó una ponencia acerca de los recintos amurallados del alcázar y la profesora Magdalena Valor expuso una comunicación sobre las fortificaciones medievales de toda la ciudad, en la cual insistió en el origen árabe omeya del alcázar de Arriba: "A diferencia de otros sectores el origen de este emplazamiento como reducto defensivo y palatino, debió arrancar de la época Omeya, probablemente del siglo IX"15.

Este congreso de historia medieval de Carmona despertó de nuevo el interés de las investigaciones arqueológicas ya que en 1998 tuvieron lugar unas nuevas excavaciones en el alcázar dirigidas por Rocío Anglada y Juan Manuel Román. Las excavaciones en esta ocasión tuvieron lugar dentro del espacio palatino, pero como los propios arqueólogos admiten, los resultados de la campaña no fueron demasiado fructíferos, pues los objetivos de dichas excavaciones no respondían tanto a una rentabilización del trabajo sino a un campo de aprendizaje y acercamiento a las técnicas arqueológicas ${ }^{16}$. Eso no impidió que se lograra descubrir el pavimento de cantos rodados del palacio que mencionaba en su momento George Edward Bonsor.

En el año 2006, el profesor Rafael Cómez Ramos hizo una magnífica comparativa entre el alcázar sevillano y el carmonense. Consideró que una de las similitudes entre ambos edificios era la distribución de las estancias en torno al patio de Doncellas y el patio de la Fuente respectivamente ${ }^{17}$. Cómez Ramos, siguiendo las ideas de Hernández Díaz,

12. Cardenete y Lineros, 572 .

13. Cardenete y Lineros, 572.

14. Luis de Mora-Figueroa Williams, "El Alcázar Real de Carmona (Sevilla). La muralla exterior y su flanqueo," Archivo Hispalense, no. 243245 (1997).

15. Magdalena Valor Piechotta, "Las defensas de Carmona," Archivo Hispalense, no. 243-245 (1997): 607.

16. Rocío Anglada Curado y Juan Manuel Román Rodríguez, “Excavaciones arqueológicas de urgencia en el Alcázar de Arriba de Carmona," Anuario Arqueológico de Andalucía 1998, vol. 3, t. 2 Actividades de urgencia (2001): 931.

17. Rafael Cómez Ramos, "El Alcázar de Carmona "versus" Alcázar de Sevilla," Laboratorio de Arte, no. 8 (2006): 14. 
Sancho Corbacho, y Collantes de Terán, también va a plantear que la intervención de Pedro I en el palacio carmonense fuera una simple restauración del palacio islámico anterior. Sin duda estaba impulsado por las teorías que en esos años él mismo estaba desarrollando acerca de una posible restauración del alcázar almohade de Sevilla por parte de Pedro ${ }^{18}$.

Los años 2008 y 2009 vinieron acompañados por dos descubrimientos documentales que sin duda han cambiado el curso de la historiografía del palacio. Por un lado, Jorge Maier Allende, indagando en la Real Biblioteca de Madrid, encontró un manuscrito fechado el 28 de septiembre de 1655, titulado "Galería del Alcázar de Carmona" y escrito por el anticuario Martín Vázquez Siruela (1600-1664)19. En este manuscrito se describe cuál era la disposición que tenían los retratos del salón de Reyes del alcázar, así como su estado de conservación en el siglo XVII. Por otro lado en el año 2009, Esteban Mira Caballos ${ }^{20}$ descubrió un extenso informe redactado en el año $1592^{21}$ a raíz de la solicitud del corregidor de Carmona para exponer el estado de conservación en el que se encontraba el alcázar real. En dicho informe se realizaba una amplia descripción de muchas de las estancias y estructuras del conjunto arquitectónico. Por tanto se trata de una fuente fundamental para comprender la distribución espacial del palacio en el siglo XVII.

Ambas fuentes fueron recogidas e interpretadas por Antonio Almagro Gorbea en una publicación realizada junto con Jorge Maier Allende en el año 201422. Podemos considerar dicho artículo el último trabajo de relevancia sobre el alcázar. La mayor aportación de esta nueva publicación radica esencialmente en la factura de un nuevo levantamiento planimétrico. Recordemos que los historiadores habían estado trabajando hasta el año 2014 con el plano de George Bonsor de 1886.

La publicación de Antonio Almagro y Maier Allende, es un estudio fundamental desde el punto de vista arquitectónico, sin embargo, tras este estado de la cuestión, consideramos que el alcázar de Carmona aún adolece de un estudio histórico-artístico específico

18. Rafael Cómez Ramos, "Historia del Arte y Arqueología en los nuevos hallazgos del Alcázar de Sevilla," Archivo Hispalense, no. 273-275 (2007).

19. Jorge Maier Allende, "El Salón de Reyes del Alcázar de Carmona," Estela: Revista Cultural e Informativa de Carmona, no. extraordinario (2008): 19.

20. Esteban Mira Caballos, "Alcázares y alcaides en la Carmona moderna: noticias inéditas," Revista de Historia Militar, no. 105 (2009).

21. Doc. 1, Cámara de Castilla-Diversos 26, Archivo General de Simancas (AGS), Simancas.

22. Antonio Almagro Gorbea y Jorge Maier Allende, "El Alcázar de Carmona y su Sala de los Reyes," en Urbanismo, Arquitectura y Patrimonio en Carmona, Actas del IX congreso de Historia de Carmona, dirs. Manuel González Jiménez, Antonio Caballos Rufino, y José Antonio Ruiz de la Rosa (Sevilla: Universidad de Sevilla; Carmona: Ayuntamiento de Carmona, 2014). 
que se focalice en las transformaciones que el edificio sufrió bajo el reinado de Pedro I. Nuestro objetivo en este artículo es en primer lugar delimitar las acciones constructivas llevadas a cabo en el siglo XIV frente al resto de las obras islámicas previas o las modificaciones de los siglos posteriores. Con ello podremos comprender el papel que el alcázar carmonense jugó en el reinado del rey Pedro I, así como la repercusión que las obras proyectadas por el monarca tuvieron en la fisionomía del conjunto fortificado. Para llevar a cabo este estudio vamos a comenzar con un profundo análisis de los datos y fuentes que conservamos entre 1350 y 1369.

\section{Fuentes para el estudio del alcázar durante el reinado de Pedro I}

Lo primero a lo que nos enfrentamos al abordar el estudio del alcázar de Carmona bajo el reinado de Pedro I es una total ausencia de documentos entre 1350 y 1369. Si observamos por ejemplo el archivo municipal de Carmona podemos encontrar ocho documentos del reinado de Alfonso XI y siete del reinado de Enrique II. El último documento previo a la subida al poder del rey don Pedro está fechado en Tordesillas el 17 de agosto de 1345 y el primero inmediatamente después de la conquista de la villa por las tropas del Trastámara es de diciembre de $1372^{23}$. Sin embargo entre esas fechas, correspondientes con el reinado de Pedro I, no encontramos datos archivados, algo que parece sumamente sorprendente.

Manuel Fernández López en 1886 ya planteó que cuando entró Enrique II en Carmona: "Los bienes de los presos fueron confiscados y sus ejecutorias y papeles quemados en la plaza pública, á fin de que ni el recuerdo quedase de aquellos valientes" ${ }^{\prime 2}$. Estas afirmaciones, como averiguamos en una cita al pie, proceden de la tradición popular, sin embargo compartimos la opinión de Manuel Fernández quien afirma:

Niegan algunos lo de la quema de las ejecutorias y dicen de ella que es una invención de los de Carmona para hacer odiosa la memoria de aquel rey [Enrique II]. No lo creemos nosotros así, entre otras razones porque es muy raro que ni en el archivo municipal, ni en el de la universidad de beneficiados exista el más insignificante papel del tiempo de Pedro I, siendo así que los hay en abundancia (cédulas, privilegios rodados, albalaes, etc.) de los otros reyes ${ }^{25}$.

23. González Jiménez, Catalogo de documentación medieval, 13.

24. Fernández y López, Historia de la Ciudad, 164.

25. Fernández y López, 164. 
Esta damnatio memoriae por parte de Enrique II no resulta para nada incongruente. Tras dos años de asedio a una villa que fue la última de Castilla en mostrar la lealtad al nuevo rey, no es extraño que todos los privilegios y estatutos concedidos por el rey don Pedro a la ciudad y a los que en ella habitaban fueran reducidos a cenizas por el rey Enrique a modo de represalia. Sin embargo, y a pesar de esta ausencia documental en los archivos de la ciudad, la información que nos proporcionan las crónicas, más en concreto las crónicas de Pedro I y de Enrique II escritas por el canciller López de Ayala, nos permite trabajar con muchos datos que ayudan a clarificar nuestras investigaciones (Fig. 1):

La primera alusión a la villa de Carmona en las crónicas de Ayala se remonta al siete de mayo de 1358. Cuando el cronista narra el apresamiento de Juan Fernández de Henestrosa confirma la estancia del rey en la ciudad:

luego púsolo asi por obra, é prendió á Juan Ferrandez de Henestrosa, é levóle consigo: é fué esto un lunes siete dias de mayo deste dicho año. El Rey estaba en Carmona, é avia enviado por Doña Aldonza que estaba en Sevilla, é ella fuese para él. E sopo el Rey como Juan Ferrandez de Henestrosa era preso, é pesó le dello; ca le tenia por buen Caballero, é non avia mandado que le prendiesen ${ }^{26}$.

Un año más tarde, Pedro I ordenó el ajusticiamiento de los dos hermanos menores del conde Enrique: Juan y Pedro. Estos hijos de Alfonso XI con Leonor de Guzmán se encontraban presos en Carmona. Ayala afirma: "en este dicho año mataron en Carmona, dó estaban presos, á Don Juan é á Don Pedro sus hermanos del Rey, fijos del Rey Don Alfonso é de Doña Leonor de Guzman"27.

Más relevante aún es la reunión que Pedro I tuvo con los diputados de Niebla en Carmona el 9 de enero de 1361. Cuando el rey se dirigía desde Sevilla a la guerra contra Aragón, se detuvo para que los representantes de la villa de Niebla rindieran homenaje a su hijo Fernando, el cual tuvo con María de Henestrosa. Así lo narra Ayala: "Se detuvo al paso en Carmona, á donde hizo que concurriesen los diputados de la villa de Niebla para reconocer por Señor suyo, y prestar pleyto omenage á Don Ferrando de nuestro señor el Rey, é de Doña Maria de Henestrosa su madre: como en efecto lo hicieron en sábado nueve dias de Enero, Era de 1399- años (A. C. 1361)"28. Manuel Fernández consideró que esta reunión tuvo lugar en el salón de Reyes del alcázar ${ }^{29}$. No podemos saber si el autor

26. Pero López de Ayala, “Crónica del Rey don Pedro I con las enmiendas del Secretario Gerónimo Zurita y las correcciones y notas añadidas por Don Eugenio de Llaguno y Amirola, caballero de la Orden de Santiago, de la real academia de la Historia," en Crónicas de los reyes de Castilla desde don Alfonso el sabio, hasta los católicos don Fernando y doña Isabel, ed. Cayetano Rosell (Madrid: M. Rivadeneyra editor, 1875$), 1: 236$.

27. López de Ayala, 293.

28. López de Ayala, 324.

29. Fernández y López, Historia de la Ciudad, 283. 
Gráfica de fuentes para el estudio del alcázar de Carmona durante el reinado de Pedro I

1350 Leonor de Guzmán es encerrada en el alcázar de la Puerta de Córdoba de Carmona

7 mayo $1358 \quad$ Constancia del rey habitando en Carmona

1369 Asesinato de los infantes Juan y Pedro en el alcázar de la Puerta de Córdoba de Carmona

\begin{tabular}{ll}
\hline 9 enero 1361 & Reunión del rey con los diputados de Niebla en Carmona \\
\hline $1367-1369$ & Pedro I fortalece la villa de Carmona \\
\hline 1369 & Pedro I traslada a sus hijos y sus tesoros a la villa de Carmona \\
\hline Marzo1369. & El concejo de Carmona participa en la batalla de Montiel \\
\hline Marzo 1369 & Fortalecimiento de Martín López de Córdoba en Carmona \\
\hline 1369 & Negociaciones fallidas entre Enrique II y Martín López de Córdoba \\
\hline 1370 & Asaltos de los petristas en los alrededores de Carmona \\
\hline Octubre 1370 & Reunión de los nuncios vaticanos con Martín López en el alcázar de Arriba \\
\hline 10 noviembre 1370 & Inicio del cerco de Carmona por Enrique Il \\
\hline Mayo 1371 & Caída de Carmona \\
\hline 5 abril 1504 & Terremoto de 1504 documentado por el cronista de los Reyes Católicos Andrés Bernáldez \\
\hline 1592 & Visita de los alarifes al alcázar de Carmona para evaluar los reparos \\
\hline 28 septiembre 1655 & Descripción del salón de los Reyes por Martín Vázquez Siruela \\
\hline
\end{tabular}

Fig. 1. Gráfica de fuentes para el estudio del alcázar de Carmona durante el reinado de Pedro I. (๔ Pablo Gumiel Campos, 2019).

estaba movido por una visión romántica al asignar responsabilidades a dicho emplazamiento, o si ciertamente tenía una prueba documental que lo confirmara. Aun así es casi indudable que la reunión tuvo lugar en el alcázar de Arriba que ya parecía ser desde 1358 el lugar donde Pedro I habitaba en sus visitas a la villa. De esta fuente podemos extraer por tanto que desde 1361 había al menos una estancia en el palacio reservada al ámbito protocolario y por tanto no se trataba de una simple vivienda privada, ni un edificio meramente militar.

Desde 1361 hasta 1367 volvemos a experimentar una importante ausencia de datos acerca de la villa de Carmona. Sin embargo, a partir de esa fecha, inmersos ya en la guerra civil castellana, Pedro I comenzó a abastecer y fortalecer la ciudad. Ayala insiste en dos ocasiones acerca de ello. La primera noticia sobre el abastecimiento de Carmona tiene lugar en 1367 cuando el cronista afirma: "é otrosi el Rey Don Enrique ovo nuevas como el 
Rey Don Pedro era en Sevilla, é bastecia de cada dia la villa de Carmona"30. Un año más tarde repetía: "el Rey Don Pedro tornó á Sevilla, é siempre facia bastecer la villa de Carmona, que es á seis leguas dende, ca siempre se rescelaba que se avia de ver en algund grand

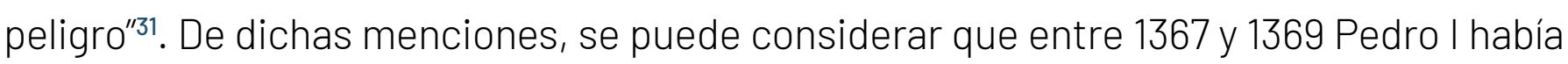
Ilevado a cabo una serie de reformas en la villa de Carmona enfocadas en su mayoría a fortalecerla y convertirla en un bastión de resistencia muy superior al que podría ser Sevilla.

Finalmente, a principios de 1369 decidió trasladar a sus hijos y sus tesoros a la villa de Carmona: "En este año sobredicho el Rey Don Pedro, antes que partiese de la cibdad de Sevilla, levó sus fijos é su tesoro todo, é muchas armas á la villa de Carmona, é dexó con ellos omes de quien se fiaba"32. De aquí podemos interpretar que las obras de fortalecimiento llevadas a cabo en la villa habían finalizado, aunque también se podría considerar que la situación de inferioridad en la guerra contra Enrique de Trastámara había acelerado su refugio.

A la muerte del rey don Pedro en marzo de 1369, la villa se fortaleció contra el nuevo rey Enrique II bajo las órdenes de Martín López de Córdoba, Al parecer el maestre de Calatrava llegó tarde a la batalla de Montiel. Cuando algunos de los hombres de Pedro I regresaban hacia Sevilla se cruzaron con él y le informaron de la muerte del monarca. Martín López al conocer los hechos decidió hacerse fuerte en Carmona, la cual había estado preparándose durante dos años, y era donde se encontraban los tesoros y los hijos del difunto rey ${ }^{33}$. Martín López, cuando llegó, tomó el control de los tres alcázares de la ciudad e inició la resistencia: “E el Maestre Don Martin López, luego que llegó en Carmona, apoderóse de todo lo que y era, asi del tesoro, como de los alcázares de la villa, que son tres, é avíalos fecho enfortalescídos mucho, é bastecidos de muchas viandas, é de muchas armas el Rey Don Pedro"34.

A finales de 1369, cuando Enrique II ya era consciente de la rebelión en la villa, intentó iniciar una serie de negociaciones con la resistencia petrista. Sin embargo, sus promesas que garantizaban un salvoconducto a Portugal, Granada o Inglaterra no fueron suficientes ${ }^{35}$. Durante el año 1370 Martín López y sus hombres llevaron a cabo numerosos

\footnotetext{
30. López de Ayala, "Crónica del Rey don Pedro I," 517.

31. López de Ayala, 529.

32. López de Ayala, 536.

33. López de Ayala, 550.

34. López de Ayala, 550.

35. Pero López de Ayala, "Crónica del Rey don Enrique II con las enmiendas del Secretario Gerónimo Zurita y las correcciones y notas añadidas por Don Eugenio de Llaguno y Amirola, caballero de la Orden de Santiago, de la real academia de la Historia," en Crónicas de los reyes de Castilla desde don Alfonso el sabio, hasta los católicos don Fernando y doña Isabel, ed. Cayetano Rosell (Madrid: M. Rivadeneyra editor, 1877), 1:3.
} 
asaltos en las localidades circundantes a Carmona, mientras Enrique II se enfrentaba a los reinos de Granada y Portugal ${ }^{36}$. Debemos mencionar también una anécdota casi cómica. En este año de 1370, cuando Enrique II decide armar galeras en Sevilla para combatir a Portugal y Granada, no consigue sacarlas a la mar, pues Pedro I, antes de marchar sobre Montiel, había decidido guardar todos los remos en la ciudad de Carmona para que su flota quedara inutilizada por parte del Trastámara: "E el Rey, después que llegó á Sevilla, mandó armar galeas, é pusieron veinte galeas en el agua; pero non pudieron aver remos, por quanto el Rey Don Pedro ficiera levar todos los remos que avia en Sevilla á la villa de Carmona" ${ }^{\prime 37}$.

En el mismo año 1370 el papa Urbano V envió a Agapito Colonna, obispo de Lisboa, junto con Bertrand de Comenges a tratar de firmar la paz entre Fernando I de Portugal y Enrique II de Castilla. Aprovechando su viaje, los obispos buscaron intervenir también en el conflicto carmonense. "E eso mesmo fueron á Carmona, por ver si podrían traer á Don Martin López de Córdoba á la merced del Rey; pero non pudieron"38. Al parecer, Martín López, ante la relevancia política de sus visitantes, decidió acogerles en el alcázar de Arriba: "Reunidos aquella misma noche en el alcázar de la puerta de Marchena los nuncios, el maestre, el canciller Mateo Ferrández, Ruy Méndez Caro, los alcaldes y los principales capitanes de la guarnición, dijeron los primeros que su viaje era motivado por el deseo que sentía Su Santidad de procurar por todos los medios posibles una avenencia honrosa entre la villa de Carmona y su rey y señor natural Enrique II"39. Estos datos expuestos por Manuel Fernández son de nuevo prueba de la existencia de un espacio protocolario en el palacio carmonense.

A partir de noviembre de 1370, Enrique II ya se encontraba a las puertas de la villa de Carmona iniciando el cerco de la misma. Así da constancia un documento firmado el 10 de noviembre de 1370 en el Real sobre Carmona ${ }^{40}$. Ayala sin embargo fecha el inicio de dicho cerco a partir de comienzos de 137141. Durante el cerco de la villa Enrique Il firmó la paz con Portugal. Así se lo hizo saber al concejo de Murcia en un documento fechado el 3 de abril 1371 en el Real sobre Carmona:

36. López de Ayala, 15.

37. López de Ayala, 15.

38. López de Ayala, 18.

39. Fernández y López, Historia de la Ciudad, 156.

40. Lope Pascual Martínez, Documentos de Enrique II, Colección de documentos para la historia del Reino de Murcia VIII (Murcia: Academia Alfonso X el Sabio, Consejo Superior de Investigaciones Científicas, 1983), 92.

41. López de Ayala, "Crónica del Rey don Enrique II," 20. 
Fazemos vos saber que oy jueues, tres dias deste mes de abril en que estamos ouiemos carta del delegado del Papa e otrosy de don Alfonso Perez de Guzman en que nos enbiaron dezir en commo las pazes son ya firmadas e sosegadas entre nos e el rey de Portogal, las quales sed çiertos que se fizieron mucho a onrra nuestra e de los nuestros regnos, pero que en estas pazes non entraron estos traydores de Carmona ${ }^{42}$.

Vemos sin embargo cómo el rey Enrique II insiste en afirmar que los traidores de Carmona aun resistían los envites del Trastámara y eran por tanto excluidos de aquella paz. En mayo de 1371 finalmente la resistencia petrista cedió. La falta de suministros se sumó a la ausencia de ayuda y apoyo militar por parte de Granada, Portugal o Inglaterra. Ayala nos cuenta cómo:

Estando el Rey Don Enrique sobre la villa de Carmona, ya las viandas fallescian á los de dentro, é muchos de los que estaban con Don Martin López se purtian dende, é io se venían para el Rey. E Don Martin López, desque vido que non se podían mas defender, é que non avia acorro ninguno de Inglaterra, nin de Granada, traxo su pleytesia con el Rey Don Enrique, que le daria la villa de Carmona, é todo lo ál que fincaba del tesoro del Rey Don Pedro (...)é que el dicho Don Martin López se fuese en salvo, é el Rey le mandase poner en otro Regno dó él quisiese ${ }^{43}$.

Enrique II aceptó la rendición, sin embargo no cumplió el acuerdo con Martín López quien junto con otros líderes petristas fue asesinado unos días más tarde en Sevilla.

La crónica de Ayala no es el único documento que deja constancia de la rendición. En una provisión real fechada el 15 de mayo de 1371, Enrique II se dirige al concejo de Murcia comunicando que el alcázar mayor de la villa, es decir el alcázar de Arriba, había sido entregado: "Fazemos vos saber que en jucues, quinze días deste mes de mayo en que estamos, nos entregaron el alcaçar mayor de aquí de Carmona en el qual estatua ençerrado el traydor de Martín Lopez, et esto mesmo nos entregaron los fijos de don Pedro con todos los otros que en el dicho alcaçar estauan"44. Este documento además nos corrobora cómo el alcázar de Arriba había servido de residencia a Martín López de Córdoba y a los hijos de Pedro I durante sus dos años de lucha.

\section{Estudio arquitectónico}

Una vez comprendidos los datos histórico-documentales con los que contamos para el estudio del alcázar durante el reinado de Pedro I, debemos proceder a un análisis de los restos arqueológicos y arquitectónicos para aclarar su posible morfología.

42. Pascual Martínez, Documentos,103.

43. López de Ayala, "Crónica del Rey don Enrique II," 21.

44. Pascual Martínez, Documentos,106. 


\section{Los perímetros amurallados}

El alcázar tenía una función esencialmente militar. El recinto palatino estaba rodeado por dos perímetros amurallados cuya superficie era cercana a los 15.000 metros cuadrados ${ }^{45}$ (Figs. 2 y 3). El recinto exterior contaba con una muralla que se extendía por los flancos sur, oeste y norte. El flanco sur hoy en día no se conserva ya que fue demolido para la construcción del parador nacional en el año 1972, sin embargo, conocemos su disposición gracias al plano de George Edward Bonsor y al dibujo de David Roberts (Fig. 4). Este lienzo meridional debía contar con una torre en el ángulo sureste que el arqueólogo inglés denominó como "torre de Rui González". Este flanco de muralla sin embargo debía encontrarse en muy malas condiciones pues, como documentó Bonsor, una falla lo atravesó a consecuencia de un terremoto en $1504^{46}$.

El lienzo occidental era el más destacado. Centrada en su mitad meridional encontramos la puerta de acceso al alcázar (Fig. 5). Esta puerta daba a la ciudad, en concreto era el remate de la vía urbana que comunicaba directamente con el alcázar de Puerta de Sevilla ${ }^{47}$. Según los planos de Bonsor, y una acuarela de David Roberts de 1833, la puerta debió tener una barbacana que la antecedía. De esta barbacana sin embargo tan solo subsiste el arranque de su muro norte ${ }^{48}$. La puerta estaba enmarcada en un arco túmido encuadrado en un alfiz. Sobre la puerta se levantaba un matacán del que aún se conservan los canes ${ }^{49}$. Detrás del arco de herradura encontramos otro arco ojival de piedra que protege la ranura por la que descendía el rastrill $0^{50}$. Entre el ángulo suroeste y la puerta de entrada había también una torre ultra semicircular con terraza almenada ${ }^{51}$.

El lienzo de muralla occidental del recinto exterior, se extiende 127 metros desde la puerta hasta su ángulo noroccidental sin ningún tipo de torre. En la esquina noroccidental de este perímetro amurallado exterior, encontramos una estructura militar propia de los siglos XV y XVI conocida como cubete. Por sus características defensivas preparadas para albergar artillería se ha datado con posterioridad al resto de la muralla,

\footnotetext{
45. Anglada Curado y Galera Navarro, "El Alcázar de Arriba," 50.

46. Afirma Bonsor: "A la derecha de la Plaza de Armas, por la parte que mira al Sur, se observa un hundimiento del terreno con 50 metros de muralla, dejando en el suelo una profunda grieta de un metro de ancho. De la muralla no queda hoy en pie más que dos grandes trozos de tapia el resto, con la torre del ángulo, rodaron desde lo alto a la Vega". George Edward Bonsor, "El terremoto de 1504 en Carmona y los Alcores," Boletín de la Real Sociedad Española de Historia Natural, no. 18 (1918):119.

47. Anglada Curado y Galera Navarro, "El Alcázar de Arriba," 50.

48. Almagro Gorbea y Maier Allende, "El Alcázar de Carmona," 283.

49. Anglada Curado y Román Rodríguez, "Excavaciones arqueológicas," 930.

50. Almagro Gorbea y Maier Allende, "El Alcázar de Carmona," 285.

51. Hernández Díaz, Sancho Corbacho, y Collantes de Terán, Catálogo arqueológico, 223.
} 


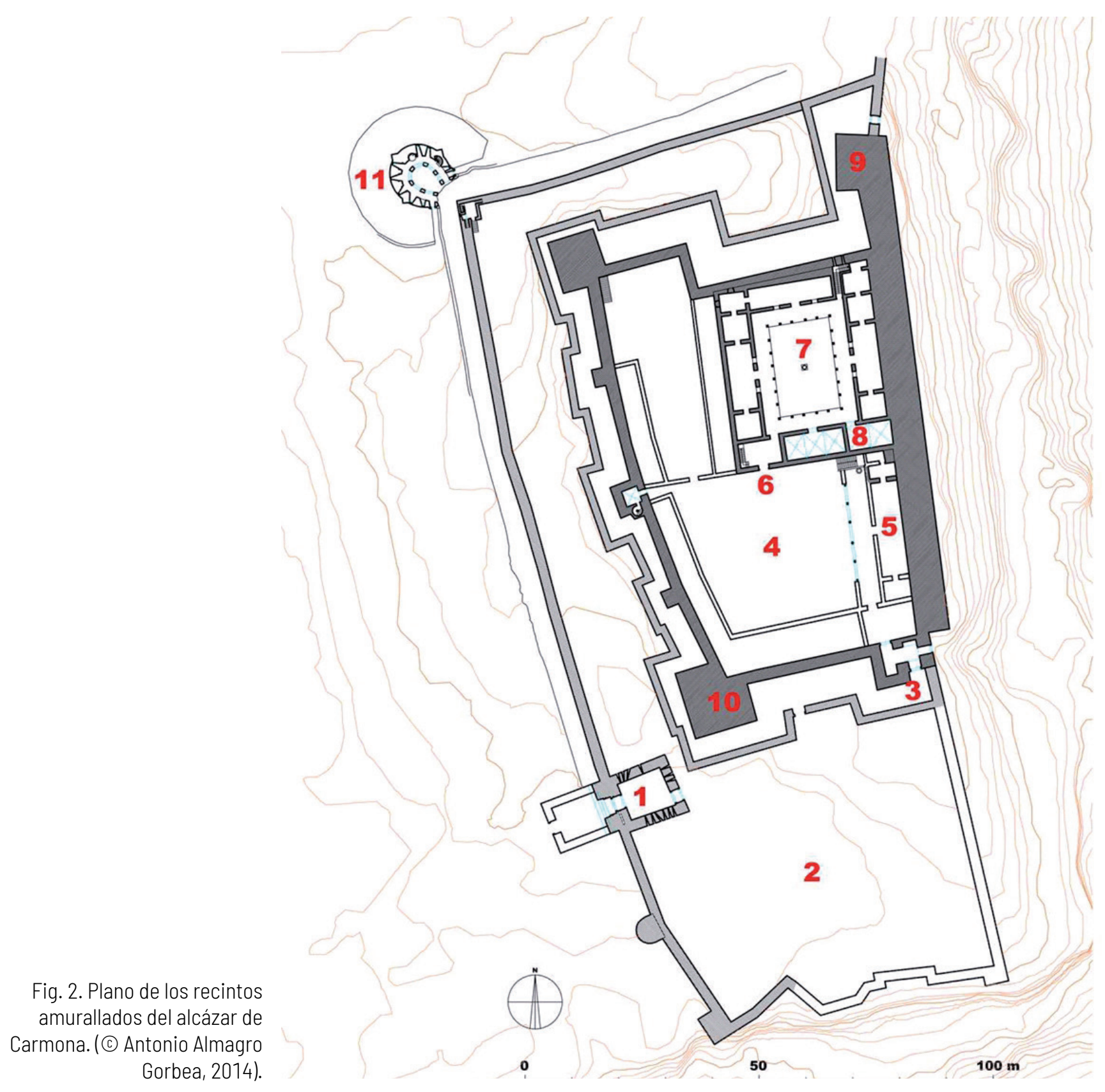

probablemente de época de los Reyes Católicos. Finalmente el lienzo septentrional se extendía otros 93 metros $^{52}$ sin ningún tipo de torre defensiva. Es posible que todo el perímetro estuviera rodeado por un foso. Como menciona Bautista Arellano en 1621: "El Alcaçar principal, esta por encima de la Puerta de Marchena, al nacimiento del sol, muy fuertemente labrado, có su barbacana, y foso, muros y torres ${ }^{\prime \prime 5}$.

La datación de este perímetro exterior es algo controvertido. Antonio Almagro y Maier Allende consideran que todos sus lienzos parecen obra de una misma fase constructiva

52. Almagro Gorbea y Maier Allende, "El Alcázar de Carmona," 283.

53. Bautista de Arellano, Antigüedades y excelencias, 101. 


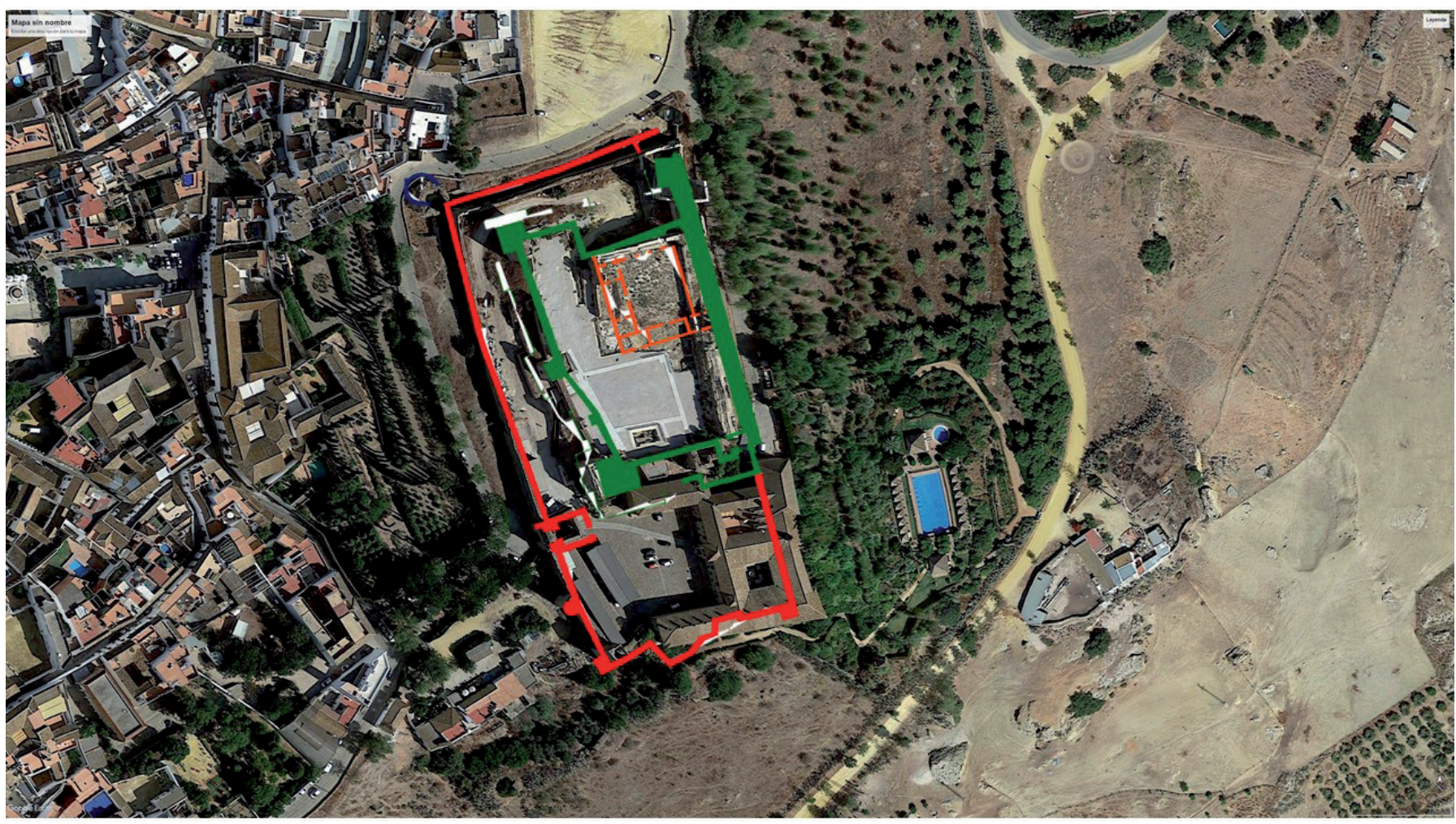

Fig. 3. Superposición del plano del alcázar de Carmona sobre una imagen de Google Earth.

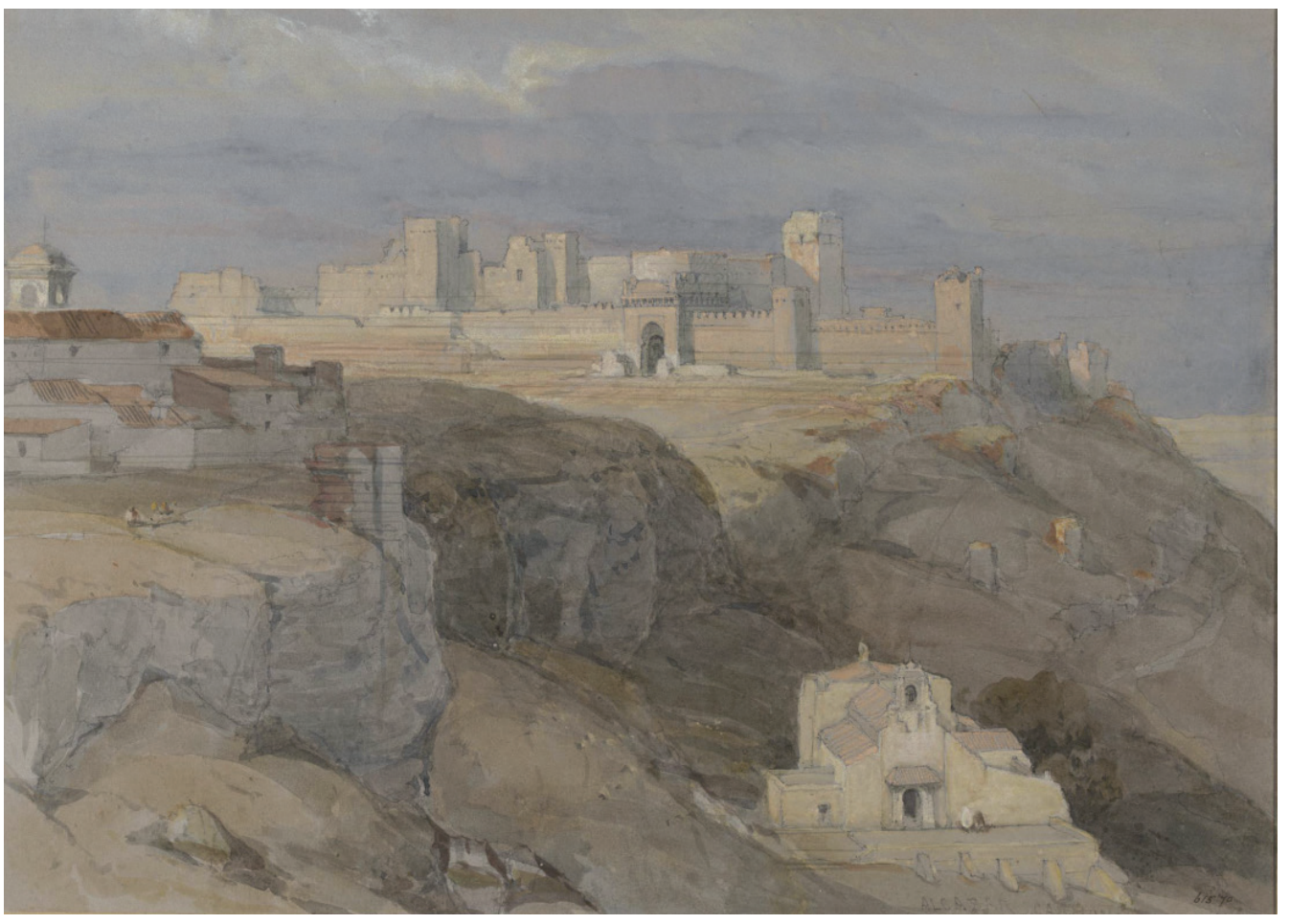

Fig. 4. Alcázar de Carmona dibujado por David Robert a comienzos del siglo XIX.

Acuarela sobre papel. (৫) Victoria and Albert Museum, London, David Roberts).

que han atribuido al reinado de Pedro $\left.\right|^{54}$. Otros autores como Luis de Mora-Figueroa sin embargo consideran que por su diseño y ejecución se trata de una obra datable durante las tres primeras décadas de la segunda mitad del siglo $X V$, y por tanto unos cien años

54. Almagro Gorbea y Maier Allende, "El Alcázar de Carmona," 283.

atrio Revista de Historia del Arte, no 26 (2020): 8 - 35 elSSN: 2659-5230. https://doi.org/10.46661/atrio.4578 
Fig. 5. Puerta de acceso al alcázar de Carmona. (৫) Pablo Gumiel Campos, 2019).

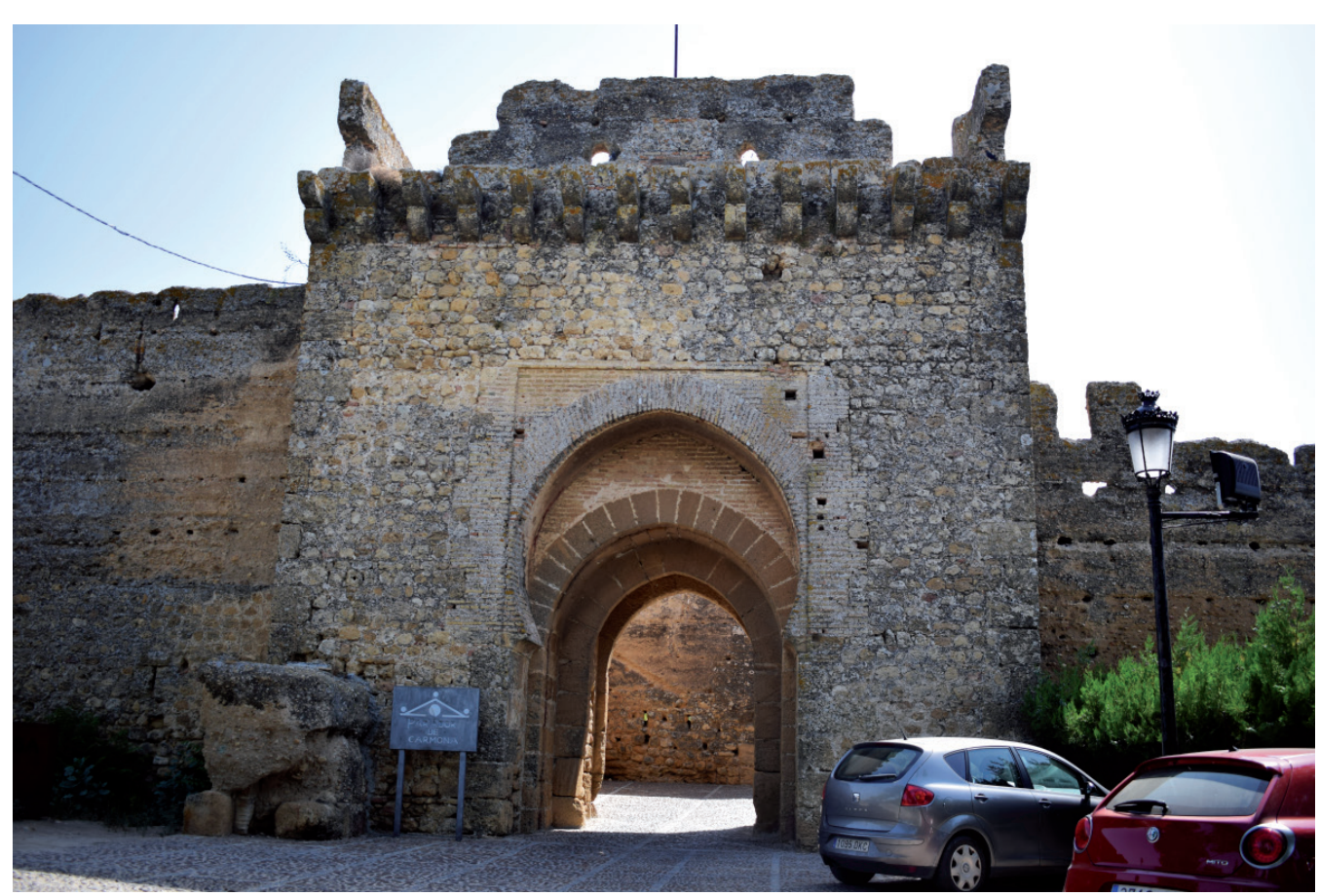

después de las reformas de Pedro ${ }^{55}$. Por la considerable actividad constructiva registrada a través de las fuentes documentales en los alcázares de Carmona entre 1367 y 1369; así como la morfología de su puerta, nos posicionamos en la opinión de Almagro y Allende, considerando el perímetro exterior una obra de refuerzo de Pedro I en las estructuras militares de su alcázar carmonense.

El espacio resultante entre el recinto amurallado exterior e interior debía actuar como plaza de armas. El perímetro interior era de mayor complejidad. Contaba cuatro grandes torres de ángulo y dos torres menores en sus lienzos oriental y occidental. La muralla además estaba precedida de un antemuro de menor altura que la rodeaba por sus lados norte, sur y oeste. Este antemuro tenía su puerta principal en el lado norte ${ }^{56}$, es decir el flanco opuesto a la entrada del recinto amurallado interior. Esto nos hablaría de un acceso de gran complejidad hasta el recinto palatino, pero no es descartable que el antemuro estuviera abierto por otros flancos para facilitar su circulación.

La torre principal del recinto amurallado interior era la torre del Homenaje (Fig. 6). Estaba situada en el ángulo noreste y controlaba el acceso del antemuro. Era la más alta y albergaba en su interior tres cuerpos cubiertos, el inferior por bóveda de medio cañón y los otros dos de arista, con unas escaleras de comunicación entre sí y con la terraza

55. Mora-Figueroa Williams, "El Alcázar Real de Carmona," 639. 56. Almagro Gorbea y Maier Allende, "El Alcázar de Carmona," 285. 


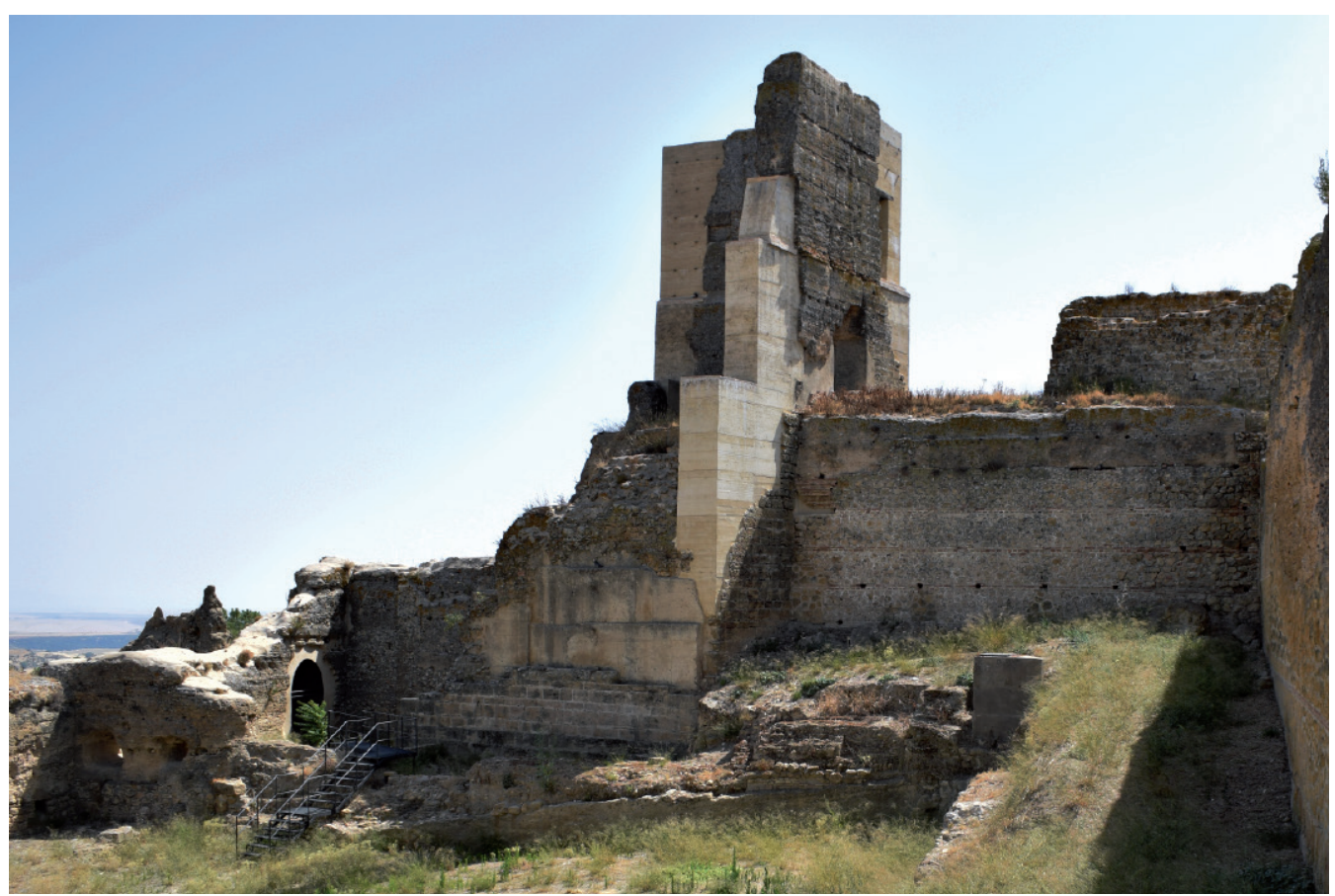

Fig. 6. Restos de la torre del Homenaje del alcázar de Carmona. () Pablo Gumiel Campos, 2019).

almenada ${ }^{57}$. En el ángulo noroeste encontrábamos la denominada torre Menor. La esquina sudoeste estaba gobernada por la torre de la Pólvora que estaba compuesta por grandes sillares y su forma era de un cuadrado imperfecto. Con su altura tenía la función de dominar toda la plaza de armas y controlarla. Por su consistencia es la que mejor se ha conservado aunque haya perdido su coronamiento.

Finalmente encontramos en el ángulo sureste la torre de la Puerta de la Piedad (Fig. 7). Esta torre controlaba el acceso al último recinto del alcázar. Se trataba de una puerta articulada a modo de recodo ${ }^{58}$ que según Fernández y López tenía "un monumental arco árabe, apoyado en dos torres y cerrado por grandes puertas llenas de clavos de cobre ó de hierro"59. Culminaban el recinto otras tres torres de menor envergadura. La torre del Trono situada en el centro del lienzo oeste mirando hacia la ciudad. La torre parece conservar restos de una bóveda, tal vez de crucería simple, cuyos arranques se conservan en los ángulos, lo que nos indica una estructuración en dos plantas bien diferenciadas. Al sur de la torre del Trono, encontramos otra de menor amplitud y finalmente la torre del Balcón, situada en el centro del lienzo este dominando la vega, en la que como veremos se emplazaba una qubba del palacio ${ }^{60}$.

57. Hernández Díaz, Sancho Corbacho, y Collantes de Terán, Catálogo arqueológico, 223.

58. Anglada Curado y Román Rodríguez, "Excavaciones arqueológicas," 930.

59. Fernández y López, Historia de la Ciudad, 156.

60. Anglada Curado y Galera Navarro, "El Alcázar de Arriba," 50. 


\section{El recinto palatino}

Una vez dentro del último recinto amurallado encontramos el palacio Real adosado a los muros norte y este del perímetro fortificado interior. El palacio estaba rodeado en sus flancos sury oeste por un patio conocido en las fuentes como el patio de los Aljibes (Fig. 8). El patio albergaba varios aljibes, dos de ellos fueron descubiertos en 1871 cuando se construyó la plaza de toros ${ }^{61}$. Sin embargo, como consideró Fernández López eran un total de cinco distribuidos por todo el espacio. Este patio además estaba empedrado con "chinas de río, blancas y negras"62 (Fig. 9).

Adosada al muro este del perímetro interior, flanqueando el patio de los Aljibes se distribuía una estancia conocida como la sala de los Azulejos. Se trataba de una nave longitudinal abierta al patio de los Aljibes a través de cinco arcos semicirculares sobre columnas ${ }^{63}$, el central de mayor radio. Esta sala debía estar cubierta por bóvedas de arista y tendría el suelo terraplenado. Así dejaron constancia los alarifes que inventariaron el estado del edificio en $1592^{64}$. El zócalo de esta estancia debió estar cubierto por un alicatado de azulejos de colores. Dan constancia de ello los restos cerámicos encontrados en torno al patio de los Aljibes. Los investigadores no han Ilegado a plantear la funcionalidad de esta nave. Por su orientación a las puertas del palacio y su disposición abierta al patio de los

61. Cómez Ramos, "El Alcázar de Carmona "versus"," 11.

62. Fernández y López, Historia de la Ciudad, 282.

63. Hoy en día es complicado vislumbrar la estructura de estos arcos, pero tomamos la palabra de los autores del catálogo arqueológico y artístico de Sevilla, quienes en 1953 quizá pudieron vislumbrar parte de esa estructura: Hernández Díaz, Sancho Corbacho, y Collantes de Terán, Catálogo arqueológico, 224.

64. Mira Caballos, "Alcázares y alcaides," 187. 


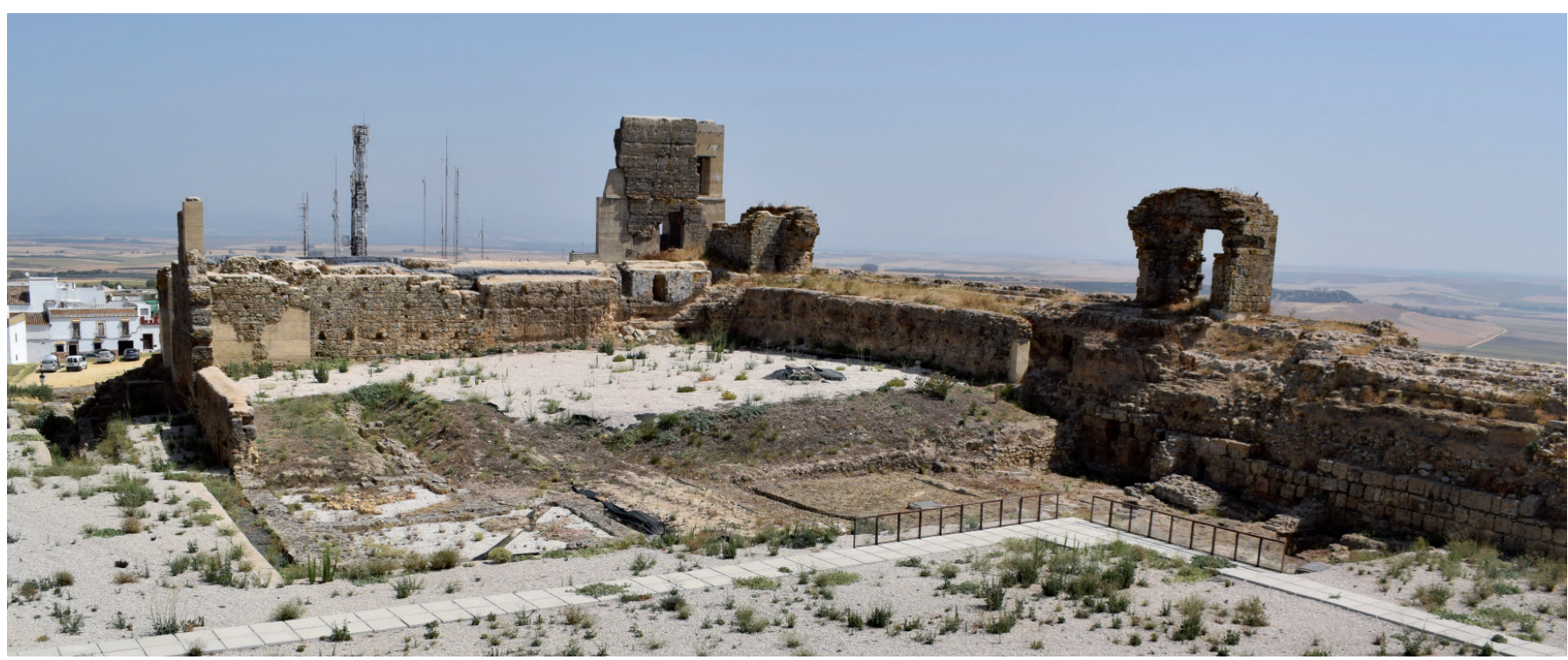

Fig. 8. Panorama general del recinto interior. Patio de los Aljibes y palacio Real del alcázar de Carmona. (@ Pablo Gumiel Campos, 2019).

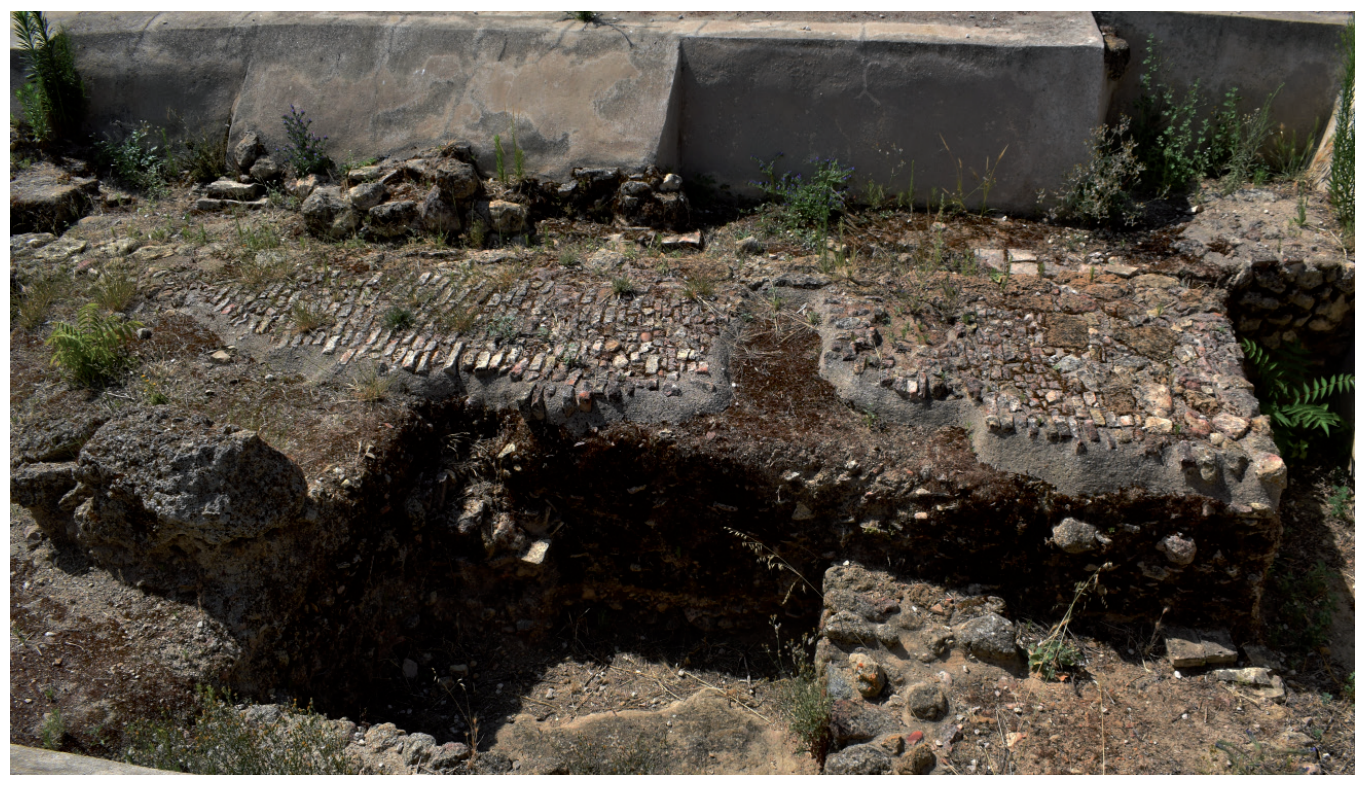

Fig. 9. Pavimento original del patio de los Aljibes del alcázar de Carmona. (๑) Pablo Gumiel Campos, 2019).

Aljibes, cabría pensar que se tratara de unas caballerizas, sin embargo la suntuosidad decorativa plantea cierta incertidumbre. En el extremo septentrional de la nave de los azulejos encontramos una escalera que subía al salón de Reyes del que más adelante hablaremos.

El palacio propiamente dicho se organizaba en torno a un patio conocido como patio de la Fuente (Fig. 10). Se trataba de un patio porticado en sus cuatro flancos con unas dimensiones de $26.40 \times 20.00$, muy similares a las del patio de Doncellas del alcázar de Sevilla $(27.66 \times 21.55)^{65}$. Según Bautista Arellano, quien pudo contemplarlo en 1621, este era un patio "có muchas colunas, cornisamento y pedestales, las puertas de las salas

65. Antonio Almagro Gorbea, "Los palacios de Pedro I. La arquitectura al servicio del poder," Anales de Historia del Arte 23, no. especial 2 (2013): 36.

atrio Revista de Historia del Arte, ํo 26 (2020): 8 - 35 elSSN: 2659-5230. https://doi.org/10.46661/atrio.4578 
Fig. 10. Planimetría del palacio Real del alcázar de Carmona. (๔ Antonio Almagro Gorbea, 2014).

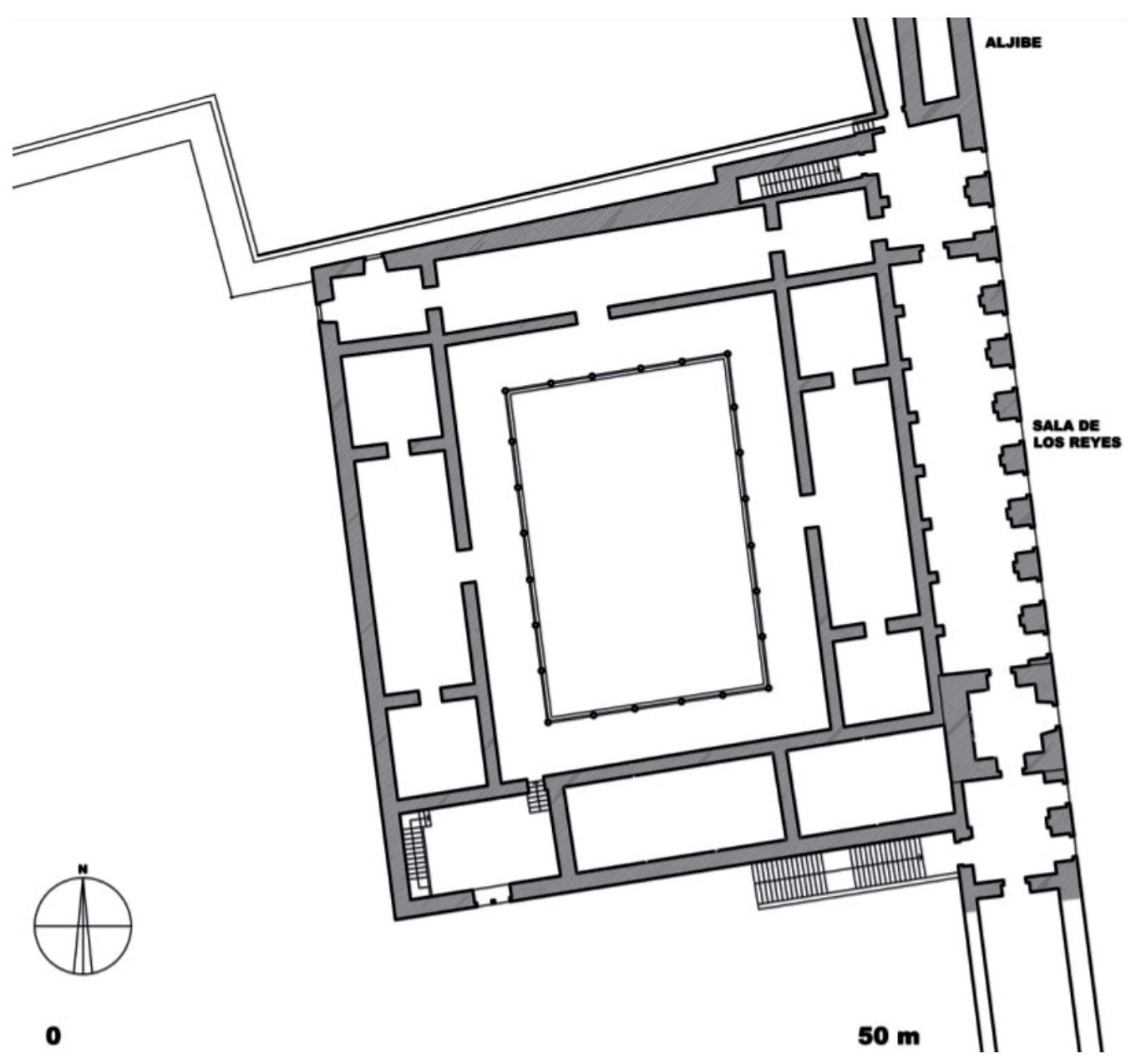

con artesones de oro, y las paredes labradas a lo Arabigo"66. Almagro plantea que las columnas y capiteles pudieran haber sido extraídas del antiguo sitio romano de Carmo. En las excavaciones de la Sociedad Arqueológica de Carmona de 1882 se encontraron restos de yesería ${ }^{67}$, lo que confirma la información de Bautista Arellano acerca de su morfología arábica. El centro del patio estaba ocupado por una fuente que estaba abastecida a través de una noria colocada en el lienzo oriental de la muralla colindante ${ }^{68}$.

Al sur del patio de la Fuente se distribuían tres estancias, el zaguán, la capilla y una sala central. El zaguán estaba precedido por una portada que se abría al patio de los Aljibes. Esta portada debió guardar una morfología similar a la de los palacios de Astudillo, Tordesillas y Sevilla. Gracias al documento redactado por los alarifes en 1592 podemos intuir parte de su composición. Debió contar con un balcón de exhibición en el piso superior. Los alarifes afirman: "Otrosí, vieron la ventana que está encima de la puerta de

66. Bautista de Arellano, Antigüedades y excelencias, 101.

67. Fernández y López, Historia de la Ciudad, 284.

68. Almagro Gorbea, "Los palacios de Pedro I," 36. 
la zaguán la cual está descubierta y hay necesidad y conviene techarla"69. Esta ventana sobre elevada da prueba de dicha composición. Este balcón además estaba protegido por un tejaroz ${ }^{70}$ al igual que en los otros palacios promocionados por el rey don Pedro. En el siglo XIX se encontraron restos epigráficos de una inscripción ilegible en caracteres árabes que pudieron pertenecer a dicha fachada ${ }^{71}$.

El zaguán estaba situado en el ángulo suroeste del palacio y contaba con dos alturas. El mismo documento de 1592 nos da constancia de la existencia de dicha planta superior: "Otrosí, vieron el entresuelo de la zaguán y conviene meter un pino y para esto y para acabar de encalar las paredes del dicha zaguán y tornar a refrescar la pintura de la madera será menester siete mil maravedís"72. A la planta superior se debía acceder por una escalera situada en su propio interior, la mampostería que hoy se encuentra adosada al muro del lado occidental del zaguán pudo corresponder a esa escalera ${ }^{73}$.

En el ángulo sureste encontrábamos la capilla privada del palacio ${ }^{74}$. Muchos autores consideran que se trataba de la mezquita primitiva convertida al culto cristiano bajo la advocación de san Juan tras la entrega de Carmona al rey Fernando 1 II $^{75}$. Juan Fernández López en 1886 encontró restos de azulejos pertenecientes a dicha capilla real76. Según Antonio Almagro toda la capilla, al igual que la sala central debió estar abovedada77, pues sostenía una terraza deambulable en el piso superior. Ciertamente en la documentación de 1592 se nos hace referencia a dichas terrazas: "Otrosí, vieron los dos terrados que están en el cuarto principal del dicho alcázar los cuales están muy maltratados"78.

En los flancos norte, este y oeste del patio de la Fuente se distribuían el resto de las estancias. El espacio mejor documentado por su registro arqueológico es el flanco occidental. En él encontrábamos una estancia longitudinal ladeada por dos alcobas alhanías. Cabe pensar que en el lado opuesto, bajo el salón de Reyes, encontráramos

69. Mira Caballos, "Alcázares y alcaides," 204.

70. Almagro Gorbea y Maier Allende, "El Alcázar de Carmona," 291.

71. Jorge Maier Allende, "Sobre los primeros estudios histórico-arqueológicos de la Carmona medieval," Archivo Hispalense, no. 80 (1997): 82.

72. Mira Caballos, "Alcázares y alcaides," 204.

73. Almagro Gorbea, "Los palacios de Pedro l," 36.

74. David Nogales Rincón, "La representación religiosa de la monarquía castellano-leonesa: la capilla real (1252-1504)" (tesis doctoral, Universidad Complutense de Madrid, 2009), 358.

75. Fernández y López, Historia de la Ciudad, 283.

76. Fernández López, "Memoria resumen," 28.

77. Almagro Gorbea, "Los palacios de Pedro l," 36.

78. Mira Caballos, "Alcázares y alcaides," 205. 
una distribución similar. Sin embargo, otros investigadores como Esteban Mira CabaIlos consideran otra posibilidad. El autor plantea la existencia de una sala idéntica al salón de Reyes del piso superior con una iconografía similar en la que estarían representadas las infantas de Castilla ${ }^{79}$. Finalmente en el lado norte George Bonsor dibujó un salón con tres vanos abiertos al patio, separados por dos columnas y una alcoba en el lado occidental. Esta es una solución bastante anómala que para Antonio Almagro recuerda las salas de los Reyes y de los Mocárabes del patio de los Leones de la Alhambra de Granada ${ }^{80}$.

El palacio contaba con dos pisos en ciertos lugares. Podemos afirmar con seguridad la existencia de una planta superior en su flanco oriental, al igual que podemos negar la presencia de un segundo piso en su lado meridional, pues tenemos constancia de la existencia de terrazas deambulables sobre las bóvedas de la capilla privada. Sin embargo es difícil aclarar cuál era la disposición del piso superior en sus lados norte y oeste $^{81}$. Había dos formas de acceder a la planta superior. La primera de ellas mediante una escalera que arrancaba desde el ángulo noreste del patio de la Fuente la cual desembocaba al norte del salón de Reyes. Esta escalera tenía un carácter privado pues su acceso se realizaba desde el interior del recinto palatino. La otra escalera subía desde el exterior. Su arranque se situaba al norte de la sala de los Azulejos y desembocaba en una estancia que precedía al salón de Reyes por el sur. Esta escalera tenía un carácter público, pues era accesible desde el exterior del palacio privado.

El piso superior del lado oriental se distribuía sobre el lienzo de muralla. Un lienzo con un grosor de 7,5 metros de anchura ${ }^{82}$. La estancia principal de la planta superior era el salón de Reyes, el cual estaba además flanqueado por otras dos estancias que actuaban a modo de antesala. El salón de Reyes estaba abovedado y tenía una terraza encima que funcionaría como adarve de la muralla ${ }^{83}$. Entre los cimientos de las bóvedas se abrian ocho balcones hacia el exterior del alcázar por su flanco oriental. En 1953 se conservaba uno de los balcones con una "cubierta de bóveda octogonal de casquetes sobre trompas de semi-bóvedas de arista"84. Este salón dominaba la campiña circundante lo que le confería un marcado simbolismo de control territoria| ${ }^{85}$. Se trata de un tipo de

\footnotetext{
79. Mira Caballos, 189.

80. Almagro Gorbea, "Los palacios de Pedro l," 37.

81. Almagro Gorbea y Maier Allende, "El Alcázar de Carmona," 293.

82. Almagro Gorbea, "Los palacios de Pedro I," 37.

83. Almagro Gorbea y Maier Allende, "El Alcázar de Carmona," 294.

84. Hernández Díaz, Sancho Corbacho, y Collantes de Terán, Catálogo arqueológico, 224.

85. Almagro Gorbea y Maier Allende, "El Alcázar de Carmona," 302.
} 


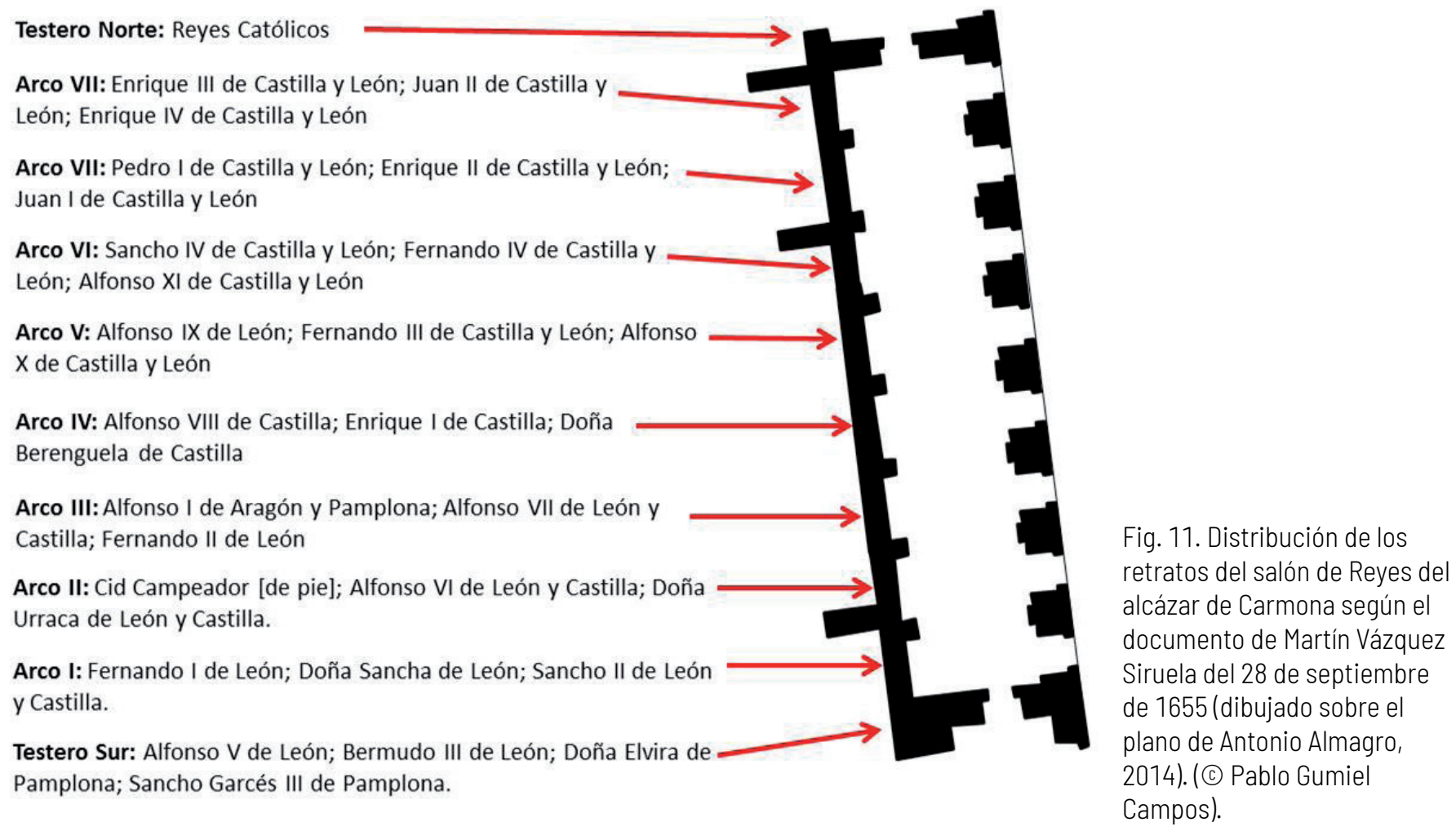

estructura que Juan Carlos Ruiz Souza ha denominado como "Andamios"86, belvederes de doble función, disfrute visual y control del entorno.

La sala fue pintada en tiempos de los Reyes Católicos con una genealogía de los reyes de Castilla. Así lo mencionaba Bautista Arellano: "Una sala hay particular en que los Catolicos reyes don Fernando y doña Isabel mandaron pintar los Reyes de España a la usança antigua de mucha vista y consideració" ${ }^{87}$. El documento de 1655 realizado por Martín Vázquez Siruela, que nosotros hemos querido sintetizar en un croquis, nos permite conocer cuál era la distribución de estas pinturas (Fig. 11).

Al sur del salón de Reyes, en el ángulo sureste del palacio, se levantaba una estancia de características muy particulares enmarcada en la denominada torre del Balcón (Fig. 12). Se ha considerado que era una antesala del salón de Reyes desde su acceso por las escaleras exteriores, sin embargo su morfología de qubba, recién descubierta por Antonio Almagro, implica un espacio de cierta entidad. Se trata de una sala cuadrada, construida con cantería y cubierta por una cúpula de ocho paños con trompas en los ángulos que debió estar hecha de ladrillo y de la que solo ha quedado la masa que la

86. Juan Carlos Ruiz Souza, "Los espacios palatinos del rey en las cortes de Castilla y Granada. Los mensajes más allá de las formas," Anales de Historia del Arte 23, no. especial 2 (2013): 328

87. Bautista de Arellano, Antigüedades y excelencias, 101. 
Fig. 12. Restos de la qubba inserta en la torre del Balcón del alcázar de Carmona. (๔) Pablo Gumiel Campos, 2019).

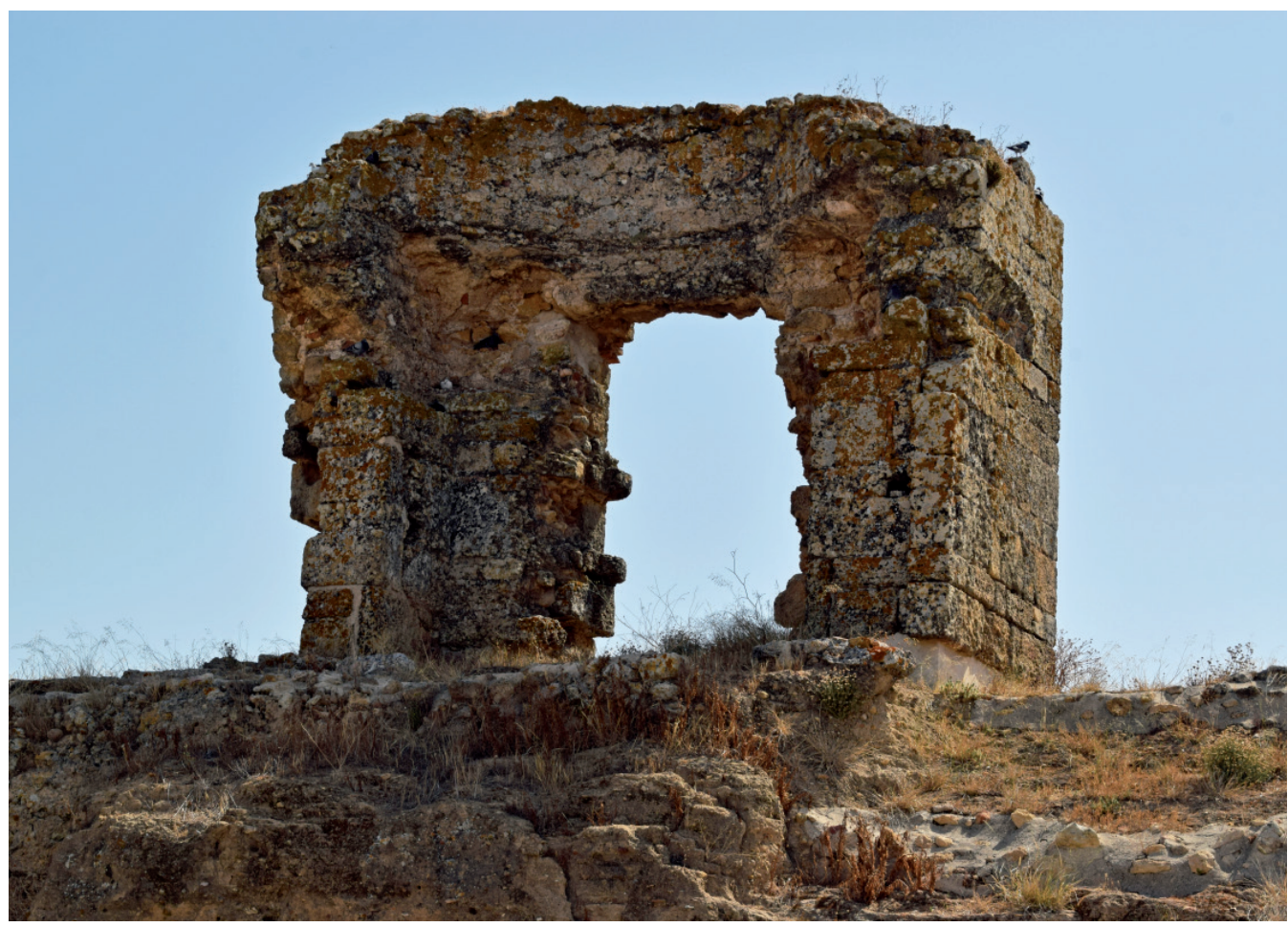

trasdosaba y rellenaba sus riñones ${ }^{88}$. La sala contaba con dos accesos. El septentrional daba al salón de Reyes mientras que el meridional desembocaba en el recibidor de la escalera exterior. Por su carácter cupulado, Antonio Almagro ha considerado que podría tratarse del aposento del rey, o que sería la estancia donde el tesoro se guardaba ${ }^{89}$. Sin embargo nos gustaría plantear otra hipótesis, la de salón del Trono.

Basamos nuestro planteamiento, en primer lugar, en la disposición de las escaleras en el palacio Real. Recordemos que la escalera exterior que arrancaba al norte de la sala de los Azulejos desembocaba en una antesala que precedía a dicha qubba. La escalera interior por el contrario comunicaba con el salón de Reyes y la qubba por el norte. Estaríamos ante un acceso público a la qubba por el sur y un acceso privado a la misma por el norte. En primer lugar, dicho acceso público rechaza la hipótesis de que fuera el dormitorio del rey. Esta distribución además es idéntica a la dispuesta en el alcázar de Sevilla en la qubba del piso superior. Por otro lado, es el único espacio cupulado dentro del palacio carmonense. Por estas razones consideramos que la qubba anexa al salón de Reyes debía actuar como salón del Trono, en el cual el rey se presentaría ante sus visitantes sin permitirles el acceso a las estancias privadas de su palacio.

88. Almagro Gorbea, "Los palacios de Pedro I," 38. 89. Almagro Gorbea, 38. 


\section{La intervención de Pedro l en el alcázar de Carmona}

Una vez planteados los estudios documentales y arquitectónicos del alcázar de Carmona, vamos a abordar el principal interrogante de nuestra investigación: ¿cuál es la intervención exacta de Pedro I en el alcázar? Toda la historiografía parece conceder un origen omeya al recinto fortificado. Tanto Magdalena Valor Piechotta ${ }^{90}$, como los autores del Catálogo arqueológico y artístico de la provincia de Sevilla consideraron que fue residencia del gobernador cordobés y después casa palacio del rey de la taifa carmonense ${ }^{91}$. Rafael Cómez Ramos ha insistido en la importancia del alcázar durante el gobierno de la familia de los Birzalies, lideres de la taifa de Carmona entre 1013 y $1067^{92}$. Es indudable por lo tanto que el alcázar de Carmona, en su aspecto militar, no es una obra de nueva planta. El primer recinto amurallado debe tener un origen islámico ya fuera de época omeya o taifa.

Por lo tanto, ¿dónde radica la intervención del rey castellano sobre este alcázar islámico? Fernández López afirmó "Pedro I, que se retiraba frecuentemente á él por lo mucho que le gustaba vivir dentro de sus muros, mostró siempre solícito interés por hermosearlo y fortalecerlo"93, Hernández, Sancho y Collantes, consideraron que "a él se debe la construcción de una puerta de entrada y de varias torres, así como el embellecimiento del Palacio - Casa Real para el que, se dice, llevó a muchos de los artistas que trabajaban en el Alcázar de Sevilla"94. Mira Caballos coincidía con estos autores unos años más tarde afirmando: "En el siglo XIV fue ennoblecido por el rey Pedro I, quien mandó traer a Carmona a algunos de los alarifes y arquitectos que por aquel entonces laboraban en su alcázar de Sevilla" ${ }^{\prime \prime 5}$.

Todos estos autores han tratado de manera muy superficial esta cuestión, por ello queremos arrojar algo más de precisión a cuál fue la intervención de Pedro I: tenemos constancia de la presencia del rey en Carmona al menos en tres ocasiones. A principios de febrero de 1358, en enero de 1361 y entre el 20 de noviembre y el 1 de diciembre de 1368. Las obras por lo tanto no debieron producirse con anterioridad al año 1358. En primer lugar ya hemos planteado que coincidimos con Antonio Almagro en que el recinto amurallado exterior fue obra del rey castellano. Para ello nos basamos en las continuas referencias a la fortificación de la villa que ofrecen las crónicas entre 1367 y 1369, así

\footnotetext{
90. Valor Piechotta, "Las defensas de Carmona," 607.

91. Hernández Díaz, Sancho Corbacho, y Collantes de Terán, Catálogo arqueológico, 221.

92. Cómez Ramos, "El Alcázar de Carmona "versus","11.

93. Fernández y López, Historia de la Ciudad, 281.

94. Hernández Díaz, Sancho Corbacho, y Collantes de Terán, Catálogo arqueológico, 221.

95. Mira Caballos, "Alcázares y alcaides," 185.
} 
como en la morfología de la puerta de acceso. El recinto amurallado interior sin embargo debió de ser previo, probablemente de época taifa.

En relación al palacio, consideramos que fue construido de modo integro por el rey don Pedro. Esto no rechaza la posibilidad de que hubiera existido un palacio previo dentro del recinto amurallado interior, sin embargo o bien fue destruido para la construcción de uno nuevo, o bien se encontraba ya en un estado ruinoso en el siglo XIV. Los argumentos en los que basamos esta idea son los siguientes:

En primer lugar, el patio de la Fuente guarda unas proporciones muy similares al patio de Doncellas del alcázar de Sevilla. Por otro lado el perímetro porticado en sus cuatro flancos, que probablemente tendría paños de sebka en su patio es algo que responde a las estructuras propias del siglo XIV y no a la tradición de origen taifa ni almohade cuyos pórticos se encuentran enfrentados tan solo en dos de sus flancos. Si consideramos que el patio de la Fuente es del siglo XIV, forzosamente el resto del palacio debe tener esta cronología, pues el patio es el eje sobre el que se disponen todas las estancias. En segundo lugar podemos hacer referencia a la estructura de acceso con un zaguán precedido por una portada situada en el ángulo noroccidental del palacio. Esta disposición de acceso en recodo con una fachada monumental es algo propio de la arquitectura petrista, y está claramente influenciado por los palacios de Astudillo y Tordesillas. Finalmente, otra de las características que identifican estas estructuras con la promoción del rey castellano es el sistema de accesos al piso superior así como la qubba en la planta alta que ejercería funciones protocolarias al igual que en Sevilla.

Podemos concluir por lo tanto que las intervenciones de Pedro I sobre el alcázar islámico de Carmona se efectuaron en dos fases distintas. La primera fase se situaría entre 1358 y 1366 y tendría como objetivo la construcción de un nuevo palacio en el interior del recinto amurallado primitivo. Podríamos considerar que en 1361, parte del palacio estaba en condiciones de habitabilidad, pues en él debió tener lugar la reunión con los diputados de Niebla. Probablemente el rey don Pedro aprovechó las obras del alcázar de Sevilla para llevar a cabo el levantamiento del palacio de Carmona. Eso implicaría también la utilización de mismos materiales, equipos de trabajo y por lo tanto arquitectos. La similitud de formas y medidas entre los palacios de Sevilla y de Carmona parece corroborar esta idea. La segunda fase constructiva se desarrollaría entre 1367 y 1369 en el contexto bélico de la guerra civil castellana y tendría una esencia de carácter exclusivamente militar. Estaríamos hablando del levantamiento del perímetro amurallado exterior, incluyendo la puerta y su barbacana. 


\section{Referencias}

Almagro Gorbea, Antonio. "Los palacios de Pedro I. La arquitectura al servicio del poder." Anales de Historia del Arte, 23, no. especial 2 (2013): 25-49.

Almagro Gorbea, Antonio, y Jorge Maier Allende. "El Alcázar de Carmona y su Sala de los Reyes." En Urbanismo, Arquitectura y Patrimonio en Carmona, Actas del IX congreso de Historia de Carmona, dirigido por Manuel González Jiménez, Antonio Caballos Rufino, y José Antonio Ruiz de la Rosa, 279-327. Sevilla: Universidad de Sevilla; Carmona: Ayuntamiento de Carmona, 2014.

Anglada Curado, Rocío, y Ventura Galera Navarro. "El Alcázar de Arriba de Carmona." Castillos de España, no. 125 (2002): 47-52.

Anglada Curado, Rocío, y Juan Manuel Román Rodríguez. "Excavaciones arqueológicas de urgencia en el Alcázar de Arriba de Carmona." Anuario arqueológico de Andalucía 1998. Vol. 3, t. 2 Actividades de urgencia (2001): 929-932.

Archivo General de Simancas (AGS). Simancas. Doc. 1, Cámara de Castilla-Diversos 26.

Bautista de Arellano, Salvador, Antigüedades y excelencias de la villa de Carmona y compendio de sus historias. Sevilla: Simón Faxarao, 1621.

Bonsor, George Edward. "El terremoto de 1504 en Carmona y los Alcores." Boletín de la Real Sociedad Española de Historia Natural, no. 18 (1918): 115-126.

Cardenete, Rosario, y Ricardo Lineros. "Avance de los resultados obtenidos en las excavaciones de los solares Jorge Bonsor no 22, Alcázar de Arriba y real no 32." Anuario arqueológico de Andalucía 1987. T. 3 Actividades de urgencia (1990): 569-572.

Cómez Ramos, Rafael. "El Alcázar de Carmona "versus" Alcázar de Sevilla." Laboratorio de Arte, no. 8 (2006): 9-30.

---. "Historia del Arte y Arqueología en los nuevos hallazgos del Alcázar de Sevilla." Archivo Hispalense, no. 273-275 (2007): 313-334.

Fernández López, Juan. "Memoria resumen de los trabajos realizados por la Sociedad Arqueológica de Carmona." En Memorias de la Sociedad Arqueológica de Carmona, 20-32. Carmona: Imp. La Verdad, 1887.

Fernández y López, Manuel. Historia de la Ciudad de Carmona, desde los tiempos más remotos hasta el reinado de Carlos I. Sevilla: Imprenta y Litografía de Gironés y Orduña, 1886.

González Jiménez, Manuel. Ordenanzas del Concejo de Carmona. Sevilla: Publicaciones de la Excma. Diputación Provincial de Sevilla, 1972.

---. Archivo de la Universidad de Beneficiados de Carmona: catálogo de documentación medieval. Sevilla: Publicaciones de la Excma. Diputación Provincial de Sevilla, 1974.

---. Catalogo de documentación medieval del Archivo Municipal de Carmona (1249-1474). SeviIla: Publicaciones de la Excma. Diputación Provincial de Sevilla, 1976.

Guerrero Chamero, Olga María. "El Alcázar de Arriba de Carmona, metodología de estudios arqueológicos durante el proceso de obra de restauración-conservación." Trabajo fin de máster, Universidad de Sevilla, 2017.

Hernández Díaz, José, Antonio Sancho Corbacho, y Francisco Collantes de Terán. Catálogo arqueológico y artístico de la provincia de Sevilla. Vol. II. Sevilla: Excelentísima Diputación Provincial de Sevilla, 1953. 
López de Ayala, Pero. "Crónica del Rey don Pedro I con las enmiendas del Secretario Gerónimo Zurita y las correcciones y notas añadidas por Don Eugenio de Llaguno y Amirola, caballero de la Orden de Santiago, de la real academia de la Historia." En Crónicas de los reyes de Castilla desde don Alfonso el sabio, hasta los católicos don Fernando y doña Isabel, editado por Cayetano Rosell. T. 1. Madrid: M. Rivadeneyra editor, 1875.

---. “Crónica del Rey don Enrique II con las enmiendas del Secretario Gerónimo Zurita y las correcciones y notas añadidas por Don Eugenio de Llaguno y Amirola, caballero de la Orden de Santiago, de la real academia de la Historia." En Crónicas de los reyes de Castilla desde don Alfonso el sabio, hasta los católicos don Fernando y doña Isabel, editado por Cayetano Rosell. T. 1. Madrid: M. Rivadeneyra editor, 1877.

Maier Allende, Jorge. "Sobre los primeros estudios histórico-arqueológicos de la Carmona medieval." Archivo Hispalense, no. 80 (1997): 79-94.

---. "El Salón de Reyes del Alcázar de Carmona." Estela: Revista Cultural e Informativa de Carmona, no. extraordinario (2008): 18-21.

Mira Caballos, Esteban. "Alcázares y alcaides en la Carmona moderna: noticias inéditas." Revista de Historia Militar, no. 105 (2009): 183-207.

Mora-Figueroa Williams, Luis de. “El Alcázar Real de Carmona(Sevilla). La muralla exterior y su flanqueo." Archivo Hispalense, no. 243-245, (1997): 637-653.

Nogales Rincón, David. "La representación religiosa de la monarquía castellano-leonesa: la capilla real (1252-1504)." Tesis doctoral, Universidad Complutense de Madrid, 2009.

Pascual Martínez, Lope. Documentos de Enrique II, Colección de documentos para la historia del Reino de Murcia VIII. Murcia: Academia Alfonso X el Sabio, Consejo Superior de Investigaciones Científicas, 1983.

Ruiz Souza, Juan Carlos. "Los espacios palatinos del rey en las cortes de Castilla y Granada. Los mensajes más allá de las formas." Anales de Historia del Arte 23, no. especial 2 (2013): 305-331.

Valor Piechotta, Magdalena. "Las defensas de Carmona." Archivo Hispalense, no. 243-245, (1997): 597-636. 